\title{
EL PARÁMETRO DE REGULARIDAD CONSTITUCIONAL COMO INSTRUMENTO PARA GARANTIZAR LOS DERECHOS HUMANOS FRENTE A LAS FORMALIDADES PROCESALES: ANÁLISIS JURISPRUDENCIAL Y DE CASO.
}

\author{
Rafael Reynoso Serrano ${ }^{1}$
}

\begin{abstract}
"Una teoría, por muy atractiva, elocuente y concisa que sea, tiene que ser rechazada o revisada si no es verdadera; de igual modo, no importa que las leyes e instituciones estén ordenadas y sean eficientes: si son injustas han de ser reformadas o abolidas."
\end{abstract}

John Rawls

\section{THE CONSTITUTIONAL REGULARITY PARAMETER AS AN INSTRUMENT TO GUARANTEE HUMAN RIGHTS IN THE FACE OF PROCEDURAL FORMALITIES: JURISPRUDENTIAL AND CASE ANALYSIS. \\ Resumen.}

Las reformas constitucionales en materia de derechos humanos han sido la base para que los juzgadores, a través de sus decisiones, interpreten las leyes de acuerdo a las necesidades de la realidad social. Con la instauración del parámetro de regularidad constitucional, se han abiertos las puertas para que los jueces resuelvan controversias de manera cada vez más justa, al no encontrarse atados con las limitaciones formales que, en ocasiones, no tienen una finalidad práctica ni benefician a las partes.

De este modo, el objetivo de este trabajo es realizar un análisis al estado jurisprudencial que impera en temas de derechos humanos y sus restricciones, para estar en condiciones de ponderar en qué casos una formalidad procesal constituye una restricción desproporcionada de algún derecho sustantivo protegido constitucionalmente, ejemplificándolo con un caso práctico.

Palabras claves: Parámetro de regularidad constitucional, debido proceso, restricciones a derechos humanos.

\footnotetext{
${ }^{1}$ Licenciado en Derecho por la Universidad de Sonora. Cuenta con Maestría en Derecho Corporativo por la Universidad La Salle, y en Juicios Orales por la Universidad Durango Santander. Cuenta con una certificación en "International Human Rights", por la Universidad de Lovaina, Bélgica. Actualmente, cursa el Doctorado en Derecho en la Universidad La Salle, cuya línea de investigación versa sobre las restricciones a derechos humanos. Ha desempeñado diversos cargos en la judicatura, y actualmente ejerce la función de Juez Segundo de Primera Instancia Penal de San Luis Río Colorado, Sonora.

${ }^{2}$ Traducida de RAWLS, John, A Theory of Justice, United States of America, Revised edition, Harvard University Press, 1999, p. 3.
} 


\begin{abstract}
.
Constitutional reforms on human rights have been the basis for judges to interpret laws according to the needs of social reality. With the establishment of the constitutional regularity parameter, the doors have been opened for judges to resolve disputes in an increasingly just way, since they are not bound by formal limitations that sometimes do not have a practical purpose or do not benefit the parties on trial.

Therefore, the objective of this paper is to analyze the jurisprudential status that prevails in human rights issues and their restrictions, in order to be able to weigh in which cases a procedural formality constitutes a disproportionate restriction of some constitutionally protected right, using a practical case as an example.
\end{abstract}

Keywords. Constitutional regularity parameter, due process, human rights restrictions.

\title{
I. Introducción
}

En los últimos años, el Estado mexicano se ha caracterizado por hacer esfuerzos legislativos ambiciosos para modernizar la impartición de justicia (reemplazando modelos escritos para dar prioridad a los orales, transparentar procesos, etc.) y materializar de manera gradual los derechos humanos, especialmente los que corresponden a los llamados grupos vulnerables.

La ya conocida reforma constitucional de junio de dos mil once en materia de derechos humanos sentó las bases para que se potencializara el desarrollo legislativo y especialmente jurisprudencial, que derivó en la creación del denominado "parámetro de regularidad constitucional", de acuerdo al cual debe analizarse la validez de las normas y actos que forman parte del orden jurídico mexicano, conformándose de los derechos 
humanos que se encuentran consagrados en la Constitución y los tratados internacionales suscritos por México. ${ }^{3}$

El establecimiento de dicho parámetro y la reforma constitucional aludida han proporcionado las herramientas necesarias para que los impartidores de justicia puedan hacer ejercicios de razonabilidad que permitan cuestionar ciertas formalidades procesales que —en muchas ocasionesirracionalmente obstaculizan el acceso a los derechos más básicos del ser humano.

Sin embargo, no debe perderse de vista que existen diversas formalidades esenciales que garantizan un debido proceso (este último cuyo acceso constituye un derecho humano por sí mismo), por lo que es tarea fundamental del operador del derecho determinar con pericia y prudencia cuándo se está ante una formalidad esencial que busca un fin razonable y válido, y cuándo se está ante aquélla que constituya un mero obstáculo, cuyo respeto vulneraría la consecución de derechos de mayor entidad.

II. Los derechos humanos y el parámetro de regularidad constitucional

En junio de dos mil once, la Constitución mexicana sufrió una importante reforma que ha sido conocida como "la reforma constitucional en materia de derechos humanos". Este cambio en diversos artículos de la Carta Magna ha traído consigo un cambio paradigmático en el reconocimiento

\footnotetext{
${ }^{3}$ DERECHOS HUMANOS CONTENIDOS EN LA CONSTITUCIÓN Y EN LOS TRATADOS INTERNACIONALES. CONSTITUYEN EL PARÁMETRO DE CONTROL DE REGULARIDAD CONSTITUCIONAL, PERO CUANDO EN LA CONSTITUCIÓN HAYA UNA RESTRICCIÓN EXPRESA AL EJERCICIO DE AQUÉLLOS, SE DEBE ESTAR A LO QUE ESTABLECE EL TEXTO CONSTITUCIONAL. Gaceta del Semanario Judicial de la Federación, Libro 5, abril de 2014, Tomo I, Materia(s): Constitucional, Tesis: P./J. 20/2014 (10a.), página: 202. Registro: 2006224.
} 
de estos derechos y en el establecimiento explícito de herramientas jurídicas para su incorporación y aplicación.

A raíz de dicho cambio, se introdujo en el texto constitucional el principio internacional pro persona, que dicta que la actividad de la autoridad debe ser interpretada siempre brindándole a las personas la protección más amplia.

Asimismo, se impuso a las autoridades la obligación de promover, respetar, proteger y garantizar los derechos humanos, de conformidad con los principios de universalidad, interdependencia, indivisibilidad y progresividad.

En vísperas de la aprobación de dicha reforma, el caso Radilla Pacheco vs. México, emitido por la Corte Interamericana de Derechos Humanos, generó la necesidad de que el Presidente de la Suprema Corte de Justicia de la Nación sometiera al Pleno una consulta para determinar el cumplimiento de dicha sentencia por parte de la judicatura federal: el famoso expediente Varios 912/2010, el cual sentó las bases para la operación práctica de la reforma constitucional sobre derechos humanos.

Cuando se resolvió dicho expediente, se estableció que los criterios de la Corte Interamericana de Derechos Humanos emitidos en los casos en los que el Estado mexicano sea parte, "son vinculantes no solamente los puntos de resolución concretos de la sentencia, sino la totalidad de los criterios contenidos en la sentencia mediante la cual se resuelve ese litigio", con lo cual, además de los derechos de fuente internacional vigentes por disposición expresa del artículo primero constitucional, también las razones del tribunal interamericano que constan en los fallos 
aludidos tienen eficacia plena para la fundamentación que todo juzgador mexicano haga en sus resoluciones. ${ }^{4}$

Por su parte, en un sentido un cuanto contrario, el catorce de noviembre de dos mil doce, la Segunda Sala de la Suprema Corte de Justicia de la Nación aprobó la jurisprudencia que establece que, cuando las disposiciones constitucionales sobre derechos humanos sean suficientes, es innecesario acudir a los instrumentos internacionales relativos puesto que el principio pro persona obliga a considerar las disposiciones más favorables y esto puede satisfacerse con las normas constitucionales. ${ }^{5}$

Finalmente, el Pleno del Alto Tribunal, en la resolución de la contradicción de tesis 293/2011, de tres de septiembre de dos mil trece, si bien, contrario a lo expresado por la Segunda Sala, admitió la existencia de un parámetro de regularidad constitucional, lo cierto es que al mismo tiempo limitó la vigencia de los derechos humanos de corte internacional, a las restricciones expresas que la Constitución mexicana estableciera. ${ }^{6}$

4 SENTENCIAS EMITIDAS POR LA CORTE INTERAMERICANA DE DERECHOS HUMANOS. SON VINCULANTES EN SUS TÉRMINOS CUANDO EL ESTADO MEXICANO FUE PARTE EN EL LITIGIO. Semanario Judicial de la Federación y su Gaceta, Libro III, diciembre de 2011, Tomo 1, Materia(s): Constitucional, Tesis: P. LXV/2011 (9a.), Página: 556. Registro: 160482

${ }^{5}$ DERECHOS HUMANOS. SU ESTUDIO A PARTIR DE LA REFORMA AL ARTÍ́CULO 10. CONSTITUCIONAL, PUBLICADA EN EL DIARIO OFICIAL DE LA FEDERACIÓN EL 10 DE JUNIO DE 2011, NO IMPLICA NECESARIAMENTE QUE SE ACUDA A LOS PREVISTOS EN INSTRUMENTOS INTERNACIONALES, SI RESULTA SUFICIENTE LA PREVISIÓN QUE SOBRE ÉSTOS CONTENGA LA CONSTITUCIÓN POLÍTICA DE LOS ESTADOS UNIDOS MEXICANOS. Semanario Judicial de la Federación y su Gaceta, Libro XVII, Febrero de 2013, Tomo 2, Materia(s): Constitucional, Tesis: 2a./J. 172/2012 (10a.), Página: 1049. Registro: 2002747

${ }^{6}$ DERECHOS HUMANOS CONTENIDOS EN LA CONSTITUCIÓN Y EN LOS TRATADOS INTERNACIONALES. CONSTITUYEN EL PARÁMETRO DE CONTROL DE REGULARIDAD CONSTITUCIONAL, PERO CUANDO EN LA CONSTITUCIÓN HAYA UNA RESTRICCIÓN EXPRESA AL EJERCICIO DE AQUÉLLOS, SE DEBE ESTAR A LO 
Al respecto, como lo externó el Ministro Zaldívar, a pesar de la limitación impuesta, con dicha resolución se permitió que en la impartición de justicia se entendiese que el rango constitucional de los derechos humanos de fuente internacional implica la anulación de todas aquellas normas que resulten contrarias a éstos y, como ya se ha abordado, se abrió la puerta para que en casos posteriores se fuera terminando de perfilar la forma en la cual los límites constitucionales operan en la práctica, pero con una base bien definida a partir de la cual deben derivar el resto de los criterios que emitan los juzgadores. ${ }^{7}$

Asimismo, dicho fallo amplió el efecto de tutela que estableció en el criterio anteriormente emitido por la consulta del expediente Varios 912/2010, al determinar que son vinculantes para todos los jueces del país todos los fallos de la Corte Interamericana de Derechos Humanos, con independencia de si en determinada causa fue o no parte el Estado mexicano.

Como dato adicional, en la academia existe un debate al respecto, pues se estima que dicho fallo generó un tipo de paradoja, si se tiene en cuenta el caso "La Última Tentación de Cristo" (Olmedo Bustos y otros) vs. Chile, donde el Tribunal Interamericano condenó al Estado chileno por establecer una restricción a la libertad de expresión en su texto constitucional, lo cual es contrario a las previsiones de la Convención Americana de Derechos Humanos, como puede apreciarse a continuación:

72. Esta Corte entiende que la responsabilidad internacional del Estado puede generarse por actos $u$ omisiones de cualquier poder $u$

QUE ESTABLECE EL TEXTO CONSTITUCIONAL. Gaceta del Semanario Judicial de la Federación, Libro 5, Abril de 2014, Tomo I, Materia(s): Constitucional, Tesis: P./J. 20/2014 (10a.), Página: 202

7 ZALDÍVAR LELO DE LARREA, Arturo, Bloque de constitucionalidad: contradicción de tesis 293/2011, en TAFOYA HERNÁNDEZ, J. Guadalupe (coord.), Elementos para el estudio del juicio de amparo, México, Suprema Corte de Justicia de la Nación, 2017, páginas 64 - 65. 
órgano de éste, independientemente de su jerarquía, que violen la Convención Americana. Es decir, todo acto u omisión, imputable al Estado, en violación de las normas del Derecho Internacional de los Derechos Humanos, compromete la responsabilidad internacional del Estado. En el presente caso ésta se generó en virtud de que el artículo 19 número 12 de la Constitución establece la censura previa en la producción cinematográfica y, por lo tanto, determina los actos de los Poderes Ejecutivo, Legislativo y Judicial.

73. A la luz de todas las consideraciones precedentes, la Corte declara que el Estado violó el derecho a la libertad de pensamiento y de expresión consagrado en el artículo 13 de la Convención Americana, en perjuicio de los señores Juan Pablo Olmedo Bustos, Ciro Colombara López, Claudio Márquez Vidal, Alex Muñoz Wilson, Matías Insunza Tagle y Hernán Aguirre Fuentes. ${ }^{8}$

Lo anterior evidencia que la jurisprudencia interamericana prohíbe la restricción de derechos humanos de corte internacional a través de las constituciones internas de los Estados, y esa jurisprudencia citada es obligatoria para México, al mismo tiempo que las decisiones jurisprudenciales de la Suprema Corte de Justicia de la Nación.

\section{El debido proceso y las formalidades esenciales del procedimiento}

Como corolario del establecimiento del parámetro de regularidad constitucional, se empezó a profundizar más en los contenidos de los derechos humanos enunciados en la Constitución mexicana; entre los que destaca el debido proceso.

El debido proceso debe considerarse como uno de los derechos más preciados en el andamiaje jurídico mexicano dado que es en sí el límite de la actividad estatal pues - como lo afirma Sergio García Ramírez- se refiere al "conjunto de requisitos que deben observarse en las instancias procesales a efectos de que las personas estén en condiciones de

${ }^{8}$ Caso "La Última Tentación de Cristo" (Olmedo Bustos y otros) vs. Chile. Serie C No. 73. Fondo, Reparaciones y Costas. 5 de febrero de 2001, párrafos 72 y 73 . 
defender adecuadamente sus derechos ante cualquier acto del Estado que pueda afectarlos". 9

Asimismo, es importante mencionar que dicho derecho debe modularse en las respectivas áreas del derecho, por lo que no siempre implica una regla por sí misma, sino que constituye un principio que debe ser interpretado de acuerdo a las necesidades que aparezcan en la materia correspondiente (i.e. la protección contra la tortura es una cuestión apremiante en materia penal, pero que no necesariamente tuviera el mismo efecto en la materia civil).

Al respecto, la Primera Sala de la Suprema Corte de Justicia de la Nación aprobó la jurisprudencia 11/2014 en sesión de siete de febrero de dos mil catorce $^{10}$, donde hizo esfuerzos para hacer una delimitación objetiva de lo que es el debido proceso, determinando que éste contiene un núcleo duro que debe observarse de manera inexcusable en todo el procedimiento jurisdiccional, el cual consiste en las formalidades esenciales del procedimiento y su cumplimiento, es decir, las cuales constituyen el mínimo de garantías que debe tener toda persona cuya esfera jurídica pretenda modificarse mediante la actividad punitiva del Estado, cuyo cumplimiento es una obligación impuesta a las autoridades.

A saber, el Máximo Tribunal sostuvo que las formalidades esenciales del procedimiento se traducen en:

a) la notificación del inicio del procedimiento y sus consecuencias;

9 GARCÍA RAMÍREZ, Sergio, El debido proceso. Criterios de la jurisprudencia interamericana, Segunda edición, México, Porrúa, 2014, p. 22.

DERECHO AL DEBIDO PROCESO. SU CONTENIDO. Gaceta del Semanario Judicial de la Federación, Libro 3, Febrero de 2014, Tomo I, Materia(s): Constitucional, Tesis: 1a./J. 11/2014 (10a.), Página: 396. Registro: 2005716. 
b) la oportunidad de ofrecer y desahogar las pruebas en que se finque la defensa;

3) la oportunidad de alegar; y

4) el dictado de una resolución que dirima las cuestiones debatidas y la existencia de un medio de impugnación. ${ }^{11}$

Por su parte, en el mismo criterio jurisprudencial se determinó que existe otro núcleo que identifica con el elenco de garantías mínimas que debe tener toda persona cuya esfera jurídica pretenda modificarse mediante la actividad punitiva del Estado, como ocurre, por ejemplo, con el derecho penal, migratorio, fiscal o administrativo, en donde se exigirá que se hagan compatibles las garantías con la materia específica del asunto. Por tanto, dentro de esta categoría de garantías del debido proceso, se identifican dos especies:

a) la primera, que corresponde a todas las personas independientemente de su condición, nacionalidad, género, edad, etcétera, dentro de las que están, por ejemplo, el derecho a contar con un abogado, a no declarar contra sí mismo o a conocer la causa del procedimiento sancionatorio; y

b) la segunda, que es la combinación del elenco mínimo de garantías con el derecho de igualdad ante la ley $y$, que protege a aquellas personas que pueden encontrarse en una situación de desventaja frente al ordenamiento jurídico, por pertenecer a algún grupo vulnerable, por ejemplo, el derecho a la notificación y asistencia consular, el derecho a contar con un traductor o intérprete, el

\footnotetext{
${ }^{11}$ La lista de formalidades esenciales del procedimiento se estableció en la tesis jurisprudencial P./J. 47/95, publicada en el Semanario Judicial de la Federación y su Gaceta, en diciembre de mil novecientos noventa y cinco, cuyo rubro es "FORMALIDADES ESENCIALES DEL PROCEDIMIENTO. SON LAS QUE GARANTIZAN UNA ADECUADA $Y$ OPORTUNA DEFENSA PREVIA AL ACTO PRIVATIVO".
} 
derecho de las niñas y los niños a que su detención sea notificada a quienes ejerzan su patria potestad y tutela, entre otras de igual naturaleza.

\section{Las restricciones a derechos humanos y el test de proporcionalidad}

Ahora bien, se debe recordar que los derechos humanos -incluso el debido proceso- pueden ser restringidos excepcionalmente por los agentes estatales o los propios particulares. Sin embargo, siempre es importante hacer un ejercicio de razonabilidad para no llegar a extremos indeseables en la protección o restricción de los derechos fundamentales de las personas.

En ocasiones, se ha dicho que los derechos humanos son mandatos de optimización, bajo el argumento de que su protección y reconocimiento constitucional presupone que sus exigencias normativas entrarán en conflicto con otras en los casos concretos, por lo que resultará necesario generar un ejercicio de ponderación para armonizar el resultado de su aplicación conjunta en cada caso en el que se presente dicho conflicto.

De ese modo, como lo ha señalado el Pleno del Alto Tribunal,

"...el legislador es competente genéricamente para emitir normas que regulan y limitan derechos, pero no puede hacerlo como prefiera, sino bajo determinadas condiciones relacionadas tanto con fines como con medios, en tanto que su labor normativa -llegado el caso- debe ser cuidadosamente examinada por la Suprema Corte de Justicia de la Nación para garantizar que los límites que de ella derivan estén justificados por la necesidad de proteger a su vez derechos e intereses constitucionalmente amparados, y no haya sido adoptada sobre bases arbitrarias o insuficientemente sensibles a su impacto en las condiciones de goce del derecho involucrado."12

${ }^{12}$ CONFLICTOS QUE INVOLUCRAN DERECHOS FUNDAMENTALES. SU RESOLUCIÓN JURÍDICA. Semanario Judicial de la Federación y su 
En ese sentido, la doctrina generada por tribunales internacionales ha permeado en la jurisprudencia mexicana, adoptando instrumentos como el "test de proporcionalidad" para efectos de tener una base objetiva a partir de la cual debe proceder todo análisis de restricciones a derechos humanos, con el fin de determinar si las medidas restrictivas son proporcionales al objetivo que se busca con ello, o no.

La Primera Sala de la Suprema Corte de Justicia de la Nación determinó adoptar la doctrina mencionada y estableció una metodología en la cual se señalan los pasos a seguir para determinar la validez o no de una restricción legislativa a los derechos humanos, señalando dos etapas a grandes rasgos.

En efecto, la primera etapa consiste en determinar si la norma impugnada incide en el alcance o contenido inicial del derecho en cuestión. En caso de determinarse que sí incide, debe pasarse al siguiente nivel, el cual consiste en examinar si en el caso concreto existe una justificación constitucional para que la medida legislativa reduzca o limite la extensión de la protección que otorga inicialmente el derecho.

Para lograr justificar la restricción a derechos humanos, debe corroborarse lo siguiente:

a) que la intervención legislativa persiga un fin constitucionalmente válido;

b) que la medida resulte idónea para satisfacer en alguna medida su propósito constitucional;

c) que no existan medidas alternativas igualmente idóneas para lograr dicho fin, pero menos lesivas para el derecho fundamental; $y$,

Gaceta, Tomo XXXIV, agosto de 2011, Materia(s): Constitucional, Tesis: P. XII/2011, Página: 23. Registro: 161368 
d) que el grado de realización del fin perseguido sea mayor al grado de afectación provocado al derecho fundamental por la medida impugnada. ${ }^{13}$

Por ello, en caso de no cumplir con dichos requisitos, la restricción deberá considerarse inválida y el derecho fundamental preservará su contenido como tal.

\section{La formalidad procesal como obstáculo para la materialización de derechos fundamentales: un caso práctico.}

Una vez establecido el antecedente doctrinario y jurisprudencial, es momento de abordar un caso práctico para un mejor entendimiento de lo hasta aqui explicado, cuyos datos fácticos son los siguientes:

En un juicio ordinario penal del sistema tradicional mixto, instaurado en contra del padre por el delito de incumplimiento de obligaciones familiares, al no haber brindado alimentos a sus hijos menores de edad, la madre de éstos y el procesado llegaron a un acuerdo para el pago de las pensiones vencidas que motivaron el juicio, para darlo por terminado.

Ambas partes se encontraron en el juzgado con el fin de que se dé legalidad al acuerdo, se sobresea el juicio y se ordene la libertad del padre. Para ello, pactaron que una cantidad se iba a pagar en ese momento y el resto se pagaría un mes después; acuerdo que se determinó como legal, se dio por terminada la controversia, se declaró firme y se puso en libertad al padre.

\footnotetext{
${ }^{13}$ TEST DE PROPORCIONALIDAD. METODOLOGÍA PARA ANALIZAR MEDIDAS LEGISLATIVAS QUE INTERVENGAN CON UN DERECHO FUNDAMENTAL. Gaceta del Semanario Judicial de la Federación, Libro 36, noviembre de 2016, Tomo II, Materia(s): Constitucional, Tesis: 1a. CCLXIII/2016 (10a.), Página: 915.
} 
Al transcurrir el mes para el cumplimiento de dicha obligación, la madre hace de conocimiento al juez que no se hizo el pago correspondiente y que por ello no se cumplió lo pactado. Ante dicha situación, el juzgador indaga los motivos de la falta de pago, a lo que el padre menciona que nunca fue su intención hacer ese pago y que solo buscaba su libertad, agregando el padre que no había nada qué hacer pues el sobreseimiento del expediente ya tenía carácter de cosa juzgada, irrevocable para el juzgador.

Ahora bien, legislativamente, el padre tiene razón en virtud de que el artículo 292 del Código de Procedimientos Penales del Estado de Sonora señala que el auto de sobreseimiento surtirá los efectos de una sentencia absolutoria y una vez ejecutoriado, tendrá valor de cosa juzgada, lo que implica que -bien o mal la decisión del juzgador de sobreseer el juicio $^{14}$ - la formalidad de la cosa juzgada es un impedimento legal para que el juez asuma cualquier otra posición en el expediente ya concluido.

Sin embargo, sostener dicha postura jurídica para respetar la institución de la cosa juzgada en ese caso, implicaría proteger una figura procesal en menoscabo de uno de los derechos más básicos de la infancia: los alimentos.

Por el contrario, de acuerdo a los párrafos octavo, noveno y décimo del artículo 40 . constitucional ${ }^{15}$, se estima que el juzgador tiene la obligación

\footnotetext{
${ }^{14}$ Debe recordarse que el Código Penal para el Estado de Sonora, en su artículo 234, establece que para que el perdón concedido por la víctima u ofendido, o representante de los menores, pueda producir sus efectos, se requerirá que el responsable pague todas las cantidades que hubiere dejado de ministrar por concepto de alimentos y otorgue fianza suficiente a juicio del juzgador, para garantizar que en lo sucesivo cumplirá con sus obligaciones

15 "En todas las decisiones y actuaciones del Estado se velará y cumplirá con el principio del interés superior de la niñez, garantizando de manera plena sus derechos. Los niños y las niñas tienen derecho a la satisfacción de sus necesidades de alimentación, salud, educación y sano esparcimiento para su desarrollo integral. Este principio deberá guiar el
} 
de propiciar el respeto a la dignidad de la niñez y el ejercicio pleno de sus derechos, con el compromiso de realizar lo que resulte necesario para tal efecto, lo que implica que el propósito directo del artículo mencionado es reconocer los ideales que en materia de los derechos de los niños han sido reconocidos a nivel internacional, para hacer real la obligación asumida por el Estado Mexicano al suscribir la Convención sobre los Derechos del Niño, en la que se comprometió a dar prioridad a los derechos de los menores de edad, a fin de asegurar que tales derechos no fueran atropellados.

Al respecto, la Primera Sala del Alto Tribunal, cuando resolvió la contradicción de tesis 496/2012 estableció que el artículo $4^{\circ}$ de la Carta Magna es terminante en señalar que el Estado, a través de sus diversas autoridades incluidas las de índole jurisdiccional, está obligado a velar y cumplir con el interés superior de los menores de edad, así como a garantizar el ejercicio de sus derechos, incluidos los de rango internacional. Asimismo, que es claro que en cualquier juicio en el que se vean involucrados sus derechos, el juzgador está obligado a cerciorarse de que cualquier decisión que se tome en torno a la niñez sea la que más convenga a sus intereses, y que, además, aun cuando la legislación ordinaria no lo establezca así, está obligado a suplir la deficiencia de la queja, a efecto de asegurarse que tales derechos no sean violentados. ${ }^{16}$

diseño, ejecución, seguimiento y evaluación de las políticas públicas dirigidas a la niñez.

Los ascendientes, tutores y custodios tienen la obligación de preservar y exigir el cumplimiento de estos derechos y principios.

El Estado otorgará facilidades a los particulares para que coadyuven al cumplimiento de los derechos de la niñez."

${ }^{16}$ MENORES DE EDAD O INCAPACES. PROCEDE LA SUPLENCIA DE LA QUEJA, EN TODA SU AMPLITUD, SIN QUE OBSTE LA NATURALEZA DE LOS DERECHOS CUESTIONADOS NI EL CARÁCTER DEL PROMOVENTE. Semanario Judicial de la Federación y su Gaceta, Novena Época, Tomo XXIII, mayo de dos mil seis, Jurisprudencia $1^{\mathrm{a}} . /$ J. 191/2005, página 167 
En efecto, el principio del interés superior de los menores de edad es una herramienta hermenéutica de gran importancia que debe ser utilizado para ampliar la esfera de protección de los derechos de éstos, cuyo respeto y cumplimiento permitirá el desarrollo progresivo de sus derechos. $^{17}$

Asimismo, no hay que perder de vista que el derecho de alimentos es uno de vital importancia pues es el presupuesto al derecho a la salud de los seres humanos, especialmente, de los menores de edad, como lo ha señalado -en términos más generales- el Comité Internacional de Derechos Económicos, Sociales y Culturales, en su observación general número 14.

En consecuencia, si bien el juicio se siguió por el delito de incumplimiento de obligaciones familiares en el que ya existe un auto que declaró ejecutoriado el sobreseimiento de la causa, lo cierto es que éste solo puede entenderse en el sentido de que se encontraba condicionado al cumplimiento del segundo pago pactado por concepto de alimentos debidos.

Por ello, se considera que por ningún motivo el juez puede dar prevalencia a la institución de la cosa juzgada (debido proceso) en menoscabo del sano desarrollo de un menor de edad, que es la finalidad de la tipificación de ese delito en el Código Penal para el Estado de Sonora.

MENORES DE EDAD O INCAPACES. LA SUPLENCIA DE LA QUEJA DEFICIENTE PROCEDE EN TODO CASO, SIN QUE OBSTE LA NATURALEZA DE LOS DERECHOS CUESTIONADOS NI EL CARÁCTER DEL PROMOVENTE. Semanario Judicial de la Federación y su Gaceta, Novena Época, Tomo XII, Julio de 2000, Tesis aislada LXXV/2000, página 16.

17 ORTEGA SORIANO, Ricardo A., Los derechos de las niñas y los niños en el derecho internacional, con especial atención al Sistema Interamericano de Protección de los Derechos Humanos, Primera edición, México, 2011, página 41. https://archivos.juridicas.unam.mx/www/bjv/libros/10/4706/11.pdf 
De hecho, esa manera de proceder ya ha sido adoptada en materias distintas a la penal por el Máximo Tribunal, donde ha señalado que dar preferencia al derecho que se deriva de la cosa juzgada, implicaría pasar por alto la obligación que el artículo 4 constitucional impuso al Estado a fin de propiciar el respeto a la dignidad de la niñez y el ejercicio pleno de sus derechos, y podría anular la obligación que el propio precepto impone a los progenitores, en el sentido de preservar el derecho que los menores de edad tienen a la satisfacción de sus necesidades de alimentación, salud, educación y sano esparcimiento, sobre todo cuando la institución procesal de la cosa juzgada que se pretende oponer frente al derecho del menor de edad, deriva de un procedimiento en el que resulta evidente que se pasaron por alto los derechos de éste. ${ }^{18}$

\section{Conclusiones}

El establecimiento del parámetro de regularidad constitucional y la implementación de métodos de análisis constitucional han generado un nuevo paradigma en la judicatura que permite a los juzgadores no estar atados a los designios de legislaciones que contravienen la Carta Magna, haciendo posible que - en muchos casos - las decisiones judiciales cada vez se acerquen más a lo que los justiciables consideran justo y no formal.

En principio, la formalidad procesal tiene como fin establecer "un piso parejo" a los contendientes de un juicio, así como dar estabilidad al sistema jurídico para hacer predecibles las decisiones de los jueces. Sin embargo, en aras de lograr esa "armonía procesal", en muchas ocasiones se llegan a extremos de establecer requisitos desproporcionados con el objetivo para el que se crearon, o se le otorga una importancia desmedida

\footnotetext{
${ }^{18}$ RECONOCIMIENTO DE PATERNIDAD. EL INTERÉS SUPERIOR DEL MENOR DEBE PREVALECER EN EL JUICIO RELATIVO FRENTE A LA INSTITUCIÓN DE LA COSA JUZGADA. Semanario Judicial de la Federación y su Gaceta, Libro XX, mayo de 2013, Tomo 1, Tesis jurisprudencial 1a./J. 28/2013 (10a.), pág. 441.
} 
a las figuras tradicionales, que terminan siendo utilizadas como lastres para los reclamos justos de la sociedad.

Así como el caso descrito en este artículo, en el ejercicio de la judicatura se presentan constantemente otros, cuya decisión es difícil en cuanto a la manera de llegar a la decisión más justa. Por ello, el juzgador siempre debe conocer y utilizar todas las herramientas a su alcance para resolver las controversias de la forma en que exige la ciudadanía y la Constitución: de manera justa, pronta e imparcial.

No hay que perder de vista que un buen juez debe buscar una transformación dentro del respeto de las leyes y la Constitución, observar las normas desde el lente de la dinámica realidad social, y entender cuáles son los valores democráticos que dichas leyes buscan proteger. ${ }^{19}$

\section{Bibliografía}

Corte Interamericana de Derechos Humanos. Caso "La Última Tentación de Cristo" (Olmedo Bustos y otros) vs. Chile. Serie C No. 73. Fondo, Reparaciones y Costas. 5 de febrero de 2001.

Caso Radilla Pacheco vs. México, Serie C No. 209.

Excepciones Preliminares, Fondo, Reparaciones y Costas. 23 de noviembre de 2009.

GARCÍA JARAMILLO, Leonardo, Activismo judicial y dogmática de los márgenes de acción: Una discusión en clave neoconstitucional, Primera edición, México, Instituto de Estudios Constitucionales, 2016. https://archivos.juridicas.unam.mx/www/bjv/libros/10/4753/9.pdf

\footnotetext{
${ }^{19}$ GARCÍA JARAMILLO, Leonardo, Activismo judicial y dogmática de los márgenes de acción: Una discusión en clave neoconstitucional, Primera edición, México, Instituto de Estudios Constitucionales, 2016, página 96. https://archivos.juridicas.unam.mx/www/bjv/libros/10/4753/9.pdf
} 
BIOLEX Revista Jurídica del Departamento de Derecho UNISON URC

Academia de Derecho Administrativo

Tercera Época Año 9. No 17 Julio -Diciembre de 2017

GARCÍA RAMÍREZ, Sergio, El debido proceso. Criterios de la jurisprudencia interamericana, Segunda edición, México, Porrúa, 2014.

ORTEGA SORIANO, Ricardo A., Los derechos de las niñas y los niños en el derecho internacional, con especial atención al Sistema Interamericano de Protección de los Derechos Humanos, Primera edición, México, 2011. https://archivos.juridicas.unam.mx/www/bjv/libros/10/4706/11.pdf

RAWLS, John, A Theory of Justice, United States of America, Revised edition, Harvard University Press, 1999.

TAFOYA HERNÁNDEZ, J. Guadalupe (coord.), Elementos para el estudio del juicio de amparo, México, Suprema Corte de Justicia de la Nación, 2017.

Semanario Judicial de la Federación y su Gaceta https://sjf.scjn.gob.mx/sjfsist/Paginas/wfContenido.aspx?control=Contenidos/ucNoticia \&file=NoticiaHistorica\&Info4=Info4 